\title{
O sottware ereader como interface para a leitura ativa em smartphone
}

\section{Ereader software as interface for active reading on smartphone}

Palavras Chave: Design de Interface, Software ereader, Leitura Ativa.

\begin{abstract}
A popularização dos smartphones configura um novo cenário para a leitura. As características destes aparelhos impõem padrões que afetam a maneira de ler e de produzir textos. A leitura de textos longos e atividades intelectuais tornam-se mais complexas. Entretanto, pesquisas indicam que o uso de smartphone para a leitura de livros cresce. A interface de um livro digital é composta por níveis que compreendem o software ereader. Este estudo objetiva a análise de um exemplar deste tipo de software ereader como interface para a leitura ativa em smartphone. Este tipo de leitura é típica de estudantes e trabalhadores intelectuais, e envolve além da leitura, atividades de comparação de textos, anotações, etc. Os resultados indicam que o smartphone não pode apoiar totalmente o processo de leitura ativa. Porém, o software ereader oferece recursos que podem amenizar as fragilidades do smartphone e viabilizar o uso do dispositivo como suporte na leitura ativa.
\end{abstract}

Keywords: Interface Design, Software ereader, Active Reading.

The popularization of smartphones sets a new stage for reading. The characteristics of these devices impose patterns that affect the way of reading and producing texts. The reading of long texts and intellectual activities become more complex. However, surveys indicate that the use of smartphones for reading books grows. The interface of a digital book is made up of levels that comprise the ereader software. This study aims to analyze a sample of this type of software ereader as interface for active reading on smartphone. This type of reading is typical of students and intellectual workers, and involves reading, text-comparison, note-taking, etc. The results indicate that the smartphone can not fully support the active reading process. However, ereader software offers features that can ease the weaknesses of the smartphone and enable the use of the device as support in active reading..

\section{Introdução}

O uso de dispositivos computacionais móveis vem crescendo em todo o mundo. No Brasil, de acordo com levantamento da Fundação Getúlio Vargas em $2017^{1}$, o número de smartphones alcançou a marca de 208 milhões de aparelhos. Este número corresponde a praticamente o total de habitantes no Brasil, ou seja, existe um dispositivo móvel conectado à internet para cada brasileiro. $O$ estudo indica ainda que os smartphones correspondem a $71 \%$ dos dispositivos móveis, ao passo que notebooks e tablets compõem o percentual restante.

Atualmente, os smartphones apresentam capacidade de processamento similar aos desktops e notebooks, o que os torna aptos a contribuir na execução de tarefas de grande complexidade. Para além dos setores do marketing e serviços de instant messaging, a utilização do smartphone como ferramenta para atividades intelectuais constitui um paradigma a ser explorado por pesquisadores. Como exemplo, confirma-se a tendência da mlearning em todo o mundo: a aprendizagem em contexto móvel é objeto de pesquisa em setores de inovação tecnológica e pedagogia.

Este fenômeno mundial configura um novo cenário para a comunicação com fortes impactos sobre a cultura e o comportamento humano. A leitura em tais dispositivos muda de natureza e constitui um novo tipo de leitor (Santaella, 2013). Para este leitor, o acesso à informação se dá em qualquer lugar e à qualquer hora. Torna-se corriqueira a conexão com muitas pessoas e grupos sociais. A leitura em smartphones perpassa processos cognitivos próprios, uma vez que este novo leitor desenvolve habilidades para lidar com estímulos diversos e distribuir a atenção em tarefas variadas.

Diante deste contexto, Baron (2015) aponta enfrentamentos que este tipo de leitura apresenta quando comparada com a leitura tradicional em suporte impresso. Ainda que a disponibilidade dos smartphones ofereça a possibilidade de acesso à informação combinando portabilidade $e$ conveniência, torna-se difícil realizar um tipo de leitura contínua e que, portanto, esteja de

${ }^{1}$ http://eaesp.fgvsp.br/sites/eaesp.fgvsp.br/files/pesti2016gvciappt.pdf. Acessado em 8 de junho de 2017.

Anais do $8^{\circ} \mathrm{CIDI}$ e $8^{\circ} \mathrm{CONGIC}$

Guilherme Santa Rosa; Cristina Portugal (orgs.)

Sociedade Brasileira de Design da Informação - SBDI

Natal | Brasil | 2017

ISBN 978-85-212-1305-5
Proceedings of the $8^{\text {th }} \mathrm{CIDI}$ and $8^{\text {th }}$ CONGIC Guilherme Santa Rosa; Cristina Portugal (orgs.) Sociedade Brasileira de Design da Informação - SBDI Natal| Brazil | 2017 ISBN 978-85-212-1305-5 
acordo com certas atividades e objetivos do leitor. A dimensão reduzida da tela e o excesso de ruído informacional, entre outros fatores característicos dos smartphones, influem negativamente na experiência do usuário.

Contrariando uma possível tendência decorrente destes enfrentamentos, em levantamento de 2016 sobre o comportamento do leitor brasileiro, o Instituto Pró-Livro indica um significativo aumento do número de leitores de livros digitais, principalmente no suporte smartphone.

Diante disso, este estudo propõe uma investigação sobre a experiência de leitura em smartphone mediada pela interface de um software ereader, com base na leitura ativa. $\mathrm{O}$ conceito se refere ao tipo de leitura em que o leitor estabelece um diálogo com o autor. Tratase de um tipo de leitura profunda e característica de estudantes e trabalhadores intelectuais, no qual o leitor navega pelo texto, faz marcações, anotações e comparações entre documentos (Adler, Doren, 2010).

A leitura em dispositivo móvel é mediada por níveis distintos de interface que coordenam o processo de leitura (Stumpf, 2013). A avaliação da experiência de leitura deste estudo terá como enfoque o nível do software ereader. Será adotada a tecnologia de ebooks em formato EPUB como referência.

Para que haja uma experiência positiva de leitura, alguns requisitos devem ser atendidos de acordo com estratégias e técnicas próprias do tipo de leitura. Portanto, o presente estudo parte das seguintes questões norteadoras: (1) Quais recursos os e-readers oferecem para a leitura ativa?; (2) Em que medida estas funcionalidades correspondem aos requisitos da leitura ativa?; (3) e em que medida este ereader dá suporte à leitura ativa em smartphone?

\section{Design, Interface e leitura}

O conceito de interface tem origem no campo da informática e remete aos artefatos que envolvem a interação entre o homem e o computador. A interface tem um papel de mediação desta interação, direcionando o usuário a interagir da melhor maneira possível, de modo a ter o produto bem adaptado a suas características físicas e cognitivas (Bonsiepe, 2015). O design de interação, portanto, se refere à atividade de projetar produtos interativos que fornecem suporte às atividades cotidianas das pessoas, seja no lar ou no trabalho (Preece, Rogers, Sharp, 2013).

Projetar a interação implica em atuar no sistema de comunicação de um artefato, isto é, no design da informação. Sendo assim, o suporte ao usuário traduz-se em garantir a efetividade da comunicação, viabilizando os processos de percepção, leitura, compreensão, memorização e uso da informação apresentada (Frascara, 2011).

Contudo, cabe salientar que o papel do design da interação na leitura é decisivo no processo não somente na dimensão simbólica e estética. Características que se situam além do texto incentivam os leitores a certas atividades. A interface, compreendida como a expressão da estrutura de um texto, orienta o usuário em seu percurso de leitura (Lupton, 2014). Recursos como títulos, tabelas, listas, botões, menus e links, se bem projetados, sugerem modos e possibilidades de interação, tornando possível um fluxo de leitura eficiente e eficaz.

\section{Desafios do Smartphone para a leitura}

O smartphone pode ser comparado a um canivete suiço (Ballard, 2007). Isso significa que o mesmo tem um caráter extremamente útil, provendo uma série de ferramentas compactadas em um único volume que pode ser carregado com facilidade. Contudo, estas ferramentas estão longe de oferecer uma alta performance ao usuário. A faca de um canivete, por exemplo, não oferece a mesma qualidade de corte de uma faca de cozinha, muito menos se encaixa tão bem ao manuseio.

Da mesma maneira, as atividades realizadas no smartphone enfrentam certas limitações, em grande parte por conta da redução das dimensões da tela. A pouca quantidade de texto disposta na tela do aparelho reduz a qualidade da leitura, dificultando o processo de compreensão, ainda mais quando o texto exige um esforço maior por conta do leitor (Nielsen, Bidu, 2014). Isto ocorre devido ao contexto reduzido de informação, o que força o usuário a visualizar menos dados e exigir mais de sua memória. 
Outros fatores relacionados à tela também interferem negativamente na leitura, como a necessidade de movimentar-se excessivamente pelo texto, enquanto que em um suporte maior o mesmo poderia ser visto de relance. De acordo com Nielsen e Bidu (2014), esta questão implica em problemas na navegação, uma vez que o usuário leva mais tempo buscando certo trecho de texto e acaba por sobrecarregar sua memória e desviar sua atenção para a tarefa de localização.

Assim sendo, a tela reduzida é o ponto mais crítico na interação de um smartphone. Nunes (2016) concorda com tal afirmação e indica estratégias que podem contribuir para a melhoria da leitura no design de uma interface. O levantamento da autora aponta que o uso da tela em posição horizontal, recursos para sumarização e hierarquização do conteúdo, o uso da polaridade positiva (texto escuro sobre fundo claro) e alterações tipográficas, como o tamanho e espaçamento entre caracteres, são relevantes na adequação do texto aos perfis de usuário e tipos de leitura.

\section{Interface dos Ebooks}

Stumpf (2013) propõe que a interface de um ebook apresenta três níveis distintos entre o leitor e o conteúdo, que interferem na qualidade da interação. O aparelho (hardware), como parte material e tangível que dispõe o texto em uma tela, constitui o primeiro nível. Pode ser tanto um computador de mesa (desktop) quanto um portátil (laptop), bem como no contexto móvel podem ser aparelhos ereaders dedicados ou tablets e smartphones. O segundo nível é representado pelo formato de arquivo, tais como ePUB e o PDF. Estes formatos determinam a necessidade de se usar um software eReader que decodifique os arquivos, os quais constituem o terceiro nível.

A navegação em um ebook pode ocorrer essencialmente a partir do sumário interativo ou linearmente, avançando para frente ou para trás, utilizando a metáfora de folheamento do livro. Estes recursos são fornecidos pela interface do software reader e podem incluir outros tipo de navegação, como por miniaturas de páginas (Damé, 2014). Contudo, a navegação também pode ocorrer no nível do ebook, a partir dos links que fazem parte da composição editorial, e que conduzem o leitor para um ambiente externo (Stumpf; Gonçalves, 2012).

\section{Softwares ereaders}

Além do controle da navegação, os software readers baseados em tecnologia EPUB podem apresentar outros recursos para apoio à atividade de leitura. Esses recursos variam entre diversos produtos disponíveis no mercado. Cada reader é parte de um ecossistema que envolve os diferentes níveis de interação do ebooks (Dpt, 2015). Assim, alguns alguns readers são nativos de certos aparelhos ereaders dedicados, a exemplo do kindle, e decodificam apenas determinados formatos de ebooks. Ao passo que outros são mais interoperáveis, como os readers feitos para a plataforma android, e dão uma cobertura maior a distintos formatos.

Os softwares ereaders tem as mesmas facilidades dos navegadores de internet, com a inclusão de ferramentas para o aprimoramento da leitura (Procópio, 2010). Entre as mais comuns:

- Criação de biblioteca pessoal;

- Acesso à livrarias e bibliotecas virtuais;

- Marcação de páginas

- Busca por palavras no texto;

- Customização de fontes

- Possibilidade de sublinhar textos

- Dicionário;

- Adição de notas.

\section{A experiência de leitura}

A leitura pode ser definida de muitas maneiras mas, em geral, indica o processo que tem como produto a compreensão (Leffa, 1996). Este processo se realiza na interação entre o indivíduo leitor e o texto, em uma trama de canais que conecta ambos os pontos em um fluxo bilateral de informação. O leitor possui as habilidades próprias para decodificar e dar sentido a um texto 
que, por sua vez, reflete parte de um mundo a ser conhecido. A leitura, portanto, se dá em uma relação triangular entre o leitor, o texto e a realidade. Se por um lado o leitor necessita de competências para atingir a compreensão, por outro, o texto deve manifestar qualidades que facilitem esse percurso.

\section{Tipos de Leitura}

$\mathrm{O}$ ato de ler envolve mais que retirar-se para um lugar tranquilo e permanecer meditando sobre um livro, avançando lentamente e linearmente pelas páginas. Tanto para o lazer quanto para o trabalho, a leitura segue ritmos e caminhos diversos. Um leitor retrocede e avança por um texto. Seleciona, recorta e descarta trechos de acordo com seus objetivos (Lupton, 2014).

Ao longo da história, a leitura teve participação em diversos contextos. Santaella (2013) descreve o processo de evolução da leitura em relação ao perfil perceptivo-cognitivo do leitor. A autora sintetiza a multiplicidade de perfis em quatro categorias:

1. Leitor contemplativo: se caracteriza por uma leitura meditativa. Se identifica com o livro e privilegia o abstrato e conceitual.

2. Leitor movente: o perfil da modernidade. Se relaciona ao surgimento do jornal, de linguagem objetiva, voltada ao cotidiano.

3. Leitor imersivo: fruto da era digital. Apresenta uma leitura mais seletiva e flexível.

4. Leitor ubíquo: o perfil que surge no contexto de mobilidade das redes. Está sempre conectado e com a atenção dividida.

Tendo em mente estes perfis, é compreensível que estes diferentes comportamentos impliquem em variados tipos de leitura. Segundo Baron (2015: 22), especialistas designam de muitas maneiras os tipos de leitura no que se refere a um livro. As categorias se relacionam ao comportamento e objetivos do leitor, tais como a leitura vertical (para se ter uma noção do essencial), o escaneamento (a procura por algo específico), a leitura extensiva (por entretenimento, como em um romance) e a leitura intensiva (muito concentrada no texto).

A autora agrupa estas categorias em duas, as quais chama de "leitura à espreita" e "leitura contínua". A primeira categoria designa a ação que se faz para checar se um livro é digno de leitura. Envolve escaneá-lo, dar uma rápida olhada por sumários e resumos, no sentido de ter uma ideia geral sobre do que se trata o livro. Já a leitura contínua, caracteriza o tipo de leitura que vai do começo ao fim. Este tipo pode se encaixar tanto no contexto de lazer quanto no educacional. Para a autora, este tipo de leitura oferece a oportunidade de praticar uma leitura profunda, envolvendo processos mais complexos de compreensão.

Os tipos de leitura para Baron (2015), da mesma maneira que os perfis cognitivos de Santaella (2013), tem um relação de complementação. Na experiência de leitura, estas diferentes categorias podem se apresentar como estratégias para dados objetivos de leitura. Com o aprimoramento das interfaces de leitura, uma dada experiência pode combinar diversos tipos. Ao ler um livro de ficção, por exemplo, um leitor certamente adotará um tipo de leitura contínua, porém, antes mesmo de se concentrar na narrativa, certamente ele irá conferir o índice, os títulos e outros elementos paratextuais.

\section{Leitura Ativa}

Chen et. al (2012) relatam o desenvolvimento de um ambiente para leitura que se relaciona a um processo de engajamento ativo com o conteúdo. A este tipo de leitura, os autores adotam a designação de leitura ativa (active reading). A expressão foi bastante explorada por Adler e Doren (2010) na defesa por um tipo de leitura de maior qualidade. Os autores definem a leitura ativa como uma atividade complexa e que demanda um maior esforço por parte de leitor. $\mathrm{Na}$ prática, busca-se uma maior compreensão sobre o texto, empregando cuidadosamente diversas atividades. Por afinidade de escopo, o presente estudo adotará o termo leitura ativa, uma vez que busca a adequação das interfaces digitais a este tipo de leitura geralmente executada por estudantes e trabalhadores intelectuais.

Tomando como referência a mídia, a leitura ativa é melhor suportada pelo meio impresso, uma vez que o digital não oferece com a mesma facilidade e variedade de funcionalidades que o tipo de leitura requer (Chen, et al. 2012). Atividades como anotar, intercalar escrita e leitura e comparar documentos simultaneamente são praticadas com melhor performance em papel impresso. 
Sendo assim, para que haja um processo de leitura ativa efetivo, é necessário que o suporte de leitura atenda a certos requisitos. O Quadro 01 apresenta tais requisitos de acordo com o nível de interface.

Quadro 01 - Resumo de requisitos para a leitura ativa, segundo Chen, Guimbretiere e Sellen, 2012.

\begin{tabular}{|c|c|}
\hline Nivel de Hardware & $\begin{array}{l}\text { Mobilidade, leveza, espessura fina, Aderêncla ao } \\
\text { suporte manual } \\
\text { Legibillidade } \\
\text { Suporte à escrita }\end{array}$ \\
\hline Nível de Págıına & $\begin{array}{l}\text { Leltura llnear } \\
\text { Ilustraçס̃es } \\
\text { Anotaçōes sobrepostas } \\
\text { Busca de texto } \\
\text { Retroceder para reler } \\
\text { Sugestão clnestésıca para virar página }\end{array}$ \\
\hline Nivel de Documento & $\begin{array}{l}\text { Navegação não sequenclal } \\
\text { Mapa cognitıvo (consclêncla) do conteúdo } \\
\text { Leltura vertıcal } \\
\text { Troca de estulos de leltura }\end{array}$ \\
\hline $\begin{array}{l}\text { Nivel de Espaço de } \\
\text { Trabalho }\end{array}$ & $\begin{array}{l}\text { Seleção de documentos } \\
\text { Layout espaclal } \\
\text { Extração de Informaçăo } \\
\text { Leltura de múltıplos documentos } \\
\text { Integração com fluxo de trabalho de PC }\end{array}$ \\
\hline Leltura Multt-sessăo & $\begin{array}{l}\text { Leltura em diferentes locals } \\
\text { Arquivamento } \\
\text { Recrlar espaço de trabalho de leltura }\end{array}$ \\
\hline
\end{tabular}

Chen et al. (2012) levantaram os requisitos expressados na tabela 01 para o projeto de um sistema que pudesse ser comparável ao papel no suporte à leitura ativa. Os requisitos foram aplicados para correlacionar as qualidades apresentadas por diversos aparelhos, o que levou à conclusão de que somente alguns requisitos eram suportados por cada tipo de dispositivo. Para os autores era, portanto, cabível o desenvolvimento de um sistema que pudesse convergir estas qualidades. Como resultado, foi gerado um sistema que combina as propriedades físicas dos leitores dedicados de ebook, com a tecnologia de escrita dos Tablet PC (computadores com tela sensível), e a capacidade que os sistemas de table tops (mesa interativa) tem de processar diversos documentos. Testes com usuários indicaram que o sistema cumpria com os requisitos considerados fundamentais: a portabilidade e a possibilidade de se trabalhar com múltiplos documentos ao mesmo tempo.

\section{Procedimentos Metodológicos}

O presente estudo tem como objetivo identificar quais recursos um software ereader pode oferecer para a leitura ativa e indicar possíveis enfrentamentos de seu uso em smartphone. Estão disponíveis no mercado softwares que têm qualidades semelhantes. Para o estudo, foi selecionado o software Prestigio por estar melhor ranqueado na Play Store. Este sistema organiza o ranking dos softwares por sua relevância no consumo mundial, relacionando dados sobre a quantidade de downloads, avaliações e engajamento dos usuários. Sendo assim, é possível assumir que o Prestigio representa um ereader de boa qualidade e alinhado tecnologicamente ao estado da arte dos ebooks. Ademais, o Prestigio é uma aplicativo para Android e suporta o formato EPUB, o que o torna uma opção mais adequada à perspectiva de democratização da leitura e que, portanto, serve bem ao propósito da tecnologia dos ebooks.

Dado o exposto sobre os níveis de interação propostos por Stumpf (2013), o estudo se voltará para o terceiro, que se refere ao software ereader. Relacionando esta categorização com a os requisitos para a leitura ativa indicados por Chen et al. (2012), verifica-se que alguns dos 
requisitos do nível da Página e do Documento tem relação com a interação fornecida pelo software ereader.

Quadro 02 - Requisitos relacionados aos níveis de Página e Documento

\begin{tabular}{|c|c|}
\hline Nível de Págı̀na & $\begin{array}{l}\text { Leltura llnear } \\
\text { llustraçס̄es } \\
\text { Anotaçס̄es sobrepostas } \\
\text { Busca de texto } \\
\text { Retroceder para reler } \\
\text { Sugestão clnestésıca para virar página }\end{array}$ \\
\hline Nivel de Documento & $\begin{array}{l}\text { Navegação não sequenclal } \\
\text { Mapa cognitıvo (consclêncla) do conteúdo } \\
\text { Leltura vertical } \\
\text { Troca de estllos de leltura }\end{array}$ \\
\hline
\end{tabular}

A análise será realizada, portanto, considerando a interface de leitura do software ereader acessada a partir de um smartphone regular. Não é objetivo deste estudo aprofundar-se nas característica da interface ao nível do hardware. Somente serão consideradas algumas limitações impostas pelo dispositivos, e como elas podem influenciar na experiência de leitura.

\section{Resultados}

Os dez requisitos foram agrupados no Quadro 03. Os resultados apontam que o Prestigio atende a metade dos requisitos em alto grau, ao passo que em grau médio somente um deles. A seguir apresenta-se o detalhamento.

Quadro 03 - Resultados da análise de requisitos para a leitura ativa

\section{Grau de atendimento aos requisitos da leitura ativa}

\begin{tabular}{|c|c|}
\hline Leltura linear & Alto \\
\hline llustraçōes & Alto \\
\hline Anotaçס̃es sobrepostas & Médıo \\
\hline Busca de texto & Alto \\
\hline Retroceder para reler & Babo \\
\hline Sugestão clnestésıca para virar págıına & Babo \\
\hline Navegação não sequenclal & Alto \\
\hline Mapa cognitıvo (consclêncla) do conteúdo & Babo \\
\hline Leltura vertical & Baxo \\
\hline
\end{tabular}

\section{Leitura linear}

A ação de ler linearmente se identifica com o que Baron (2015) define como leitura contínua. Se trata de um dos tipos mais básicos de leitura e segundo o levantamento de Chen et al. (2012) é bem executada em todos os tipos de dispositivo. O Prestigio oferece a possibilidade de avançar pelo texto com a interação de toque na lateral da tela para avançar e retroceder pelas páginas.

\section{llustrações}

A apresentação de imagens em tela é um dos pontos fortes dos ebooks. Com exceção dos leitores dedicados com tecnologia e-ink, as imagens podem ter boa qualidade de cores e 
resolução. O Prestigio oferece a possibilidade de ampliação de imagem, o que é fundamental para leitura em smartphone. O desvantagem se mostra na falta de suporte a imagens em SVG (Scalable Vector graphics), um formato vetorial baseado em XML especificado para web.

\section{Anotações sobrepostas}

O software não oferece a possibilidade de realizar anotações da mesma maneira em que são feitas sobre papel. Não é possível escrever a mão livre, como se comumente realiza na marginália de uma página. No entanto, é possível adicionar notas em destaques de texto como ilustra a Figura 1. As notas ficam salvas e depois podem ser acessadas em um lista através do menu.

Figura 1: destaque e notas sobre o texto.

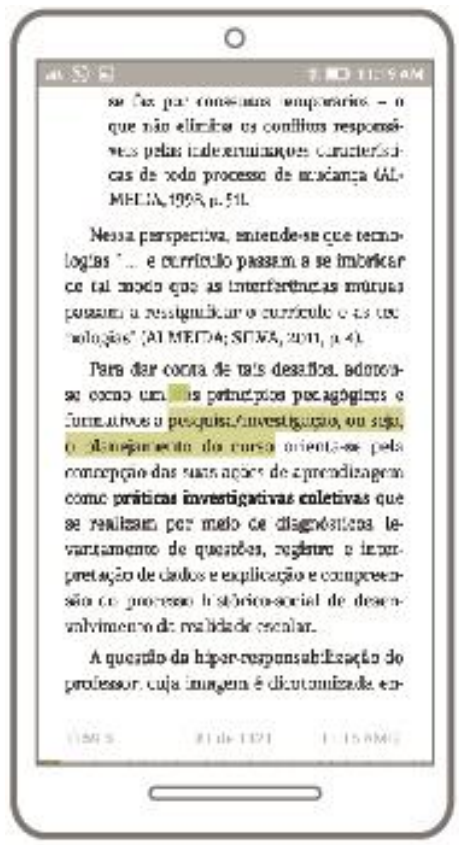

Destaque no texto.

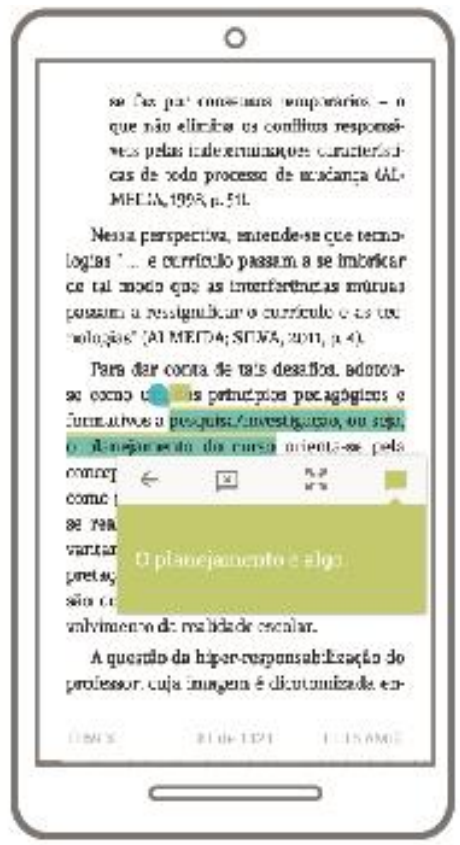

Anotação sobre o texto.

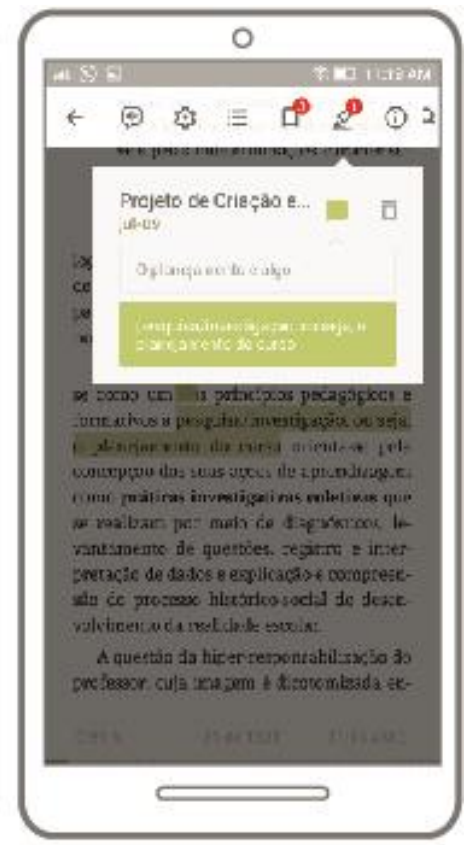

Lista de notas no menu.

\section{Busca de texto}

Este recurso é básico no meio digital e representa uma das poucas vantagens sobre o meio impresso. O Prestigio apresenta no menu, no canto superior direito, o ícone para acesso à busca.

\section{Retroceder para reler}

No processo de leitura, os olhos percorrem o texto em um movimento inconstante, realizando saltos chamados de sacadas. Quanto mais dificultado o processo de compreensão, mais frequente e maiores são as sacadas para trechos anteriores. Neste sentido, o software Prestigio tem pouco a contribuir com essa questão. Contudo, cabe ressaltar que o smartphone dificulta este processo, uma vez que a tela pequena apresenta pouco texto e exige um esforço maior para uma sacada longa. Quanto maior é a quantidade de texto disposta para o usuário, mais fácil é retroceder para reler algum trecho.

\section{Sugestão cinestésica para virar página}

Segundo Chen et. al (2012), este requisito só é bem suportado pelo papel. O Prestigio oferece a opção de mudar de página arrastando o dedo pela tela, ao passo que uma imagem de página de papel sendo virada acompanha o toque do dedo como ilustra a Figura 2. Este é um recurso comum em softwares de leitura, em que a transição de páginas é representada por uma animação de livro. Porém, este recurso não pode ser comparado à affordance de uma página impressa e toda a experiência sensorial que envolve a interação de virada de página. 


\section{CIDI $2017 \quad 8^{\mathrm{m}} \mathrm{CIDI}$

Figura 2: animação de virada de página.

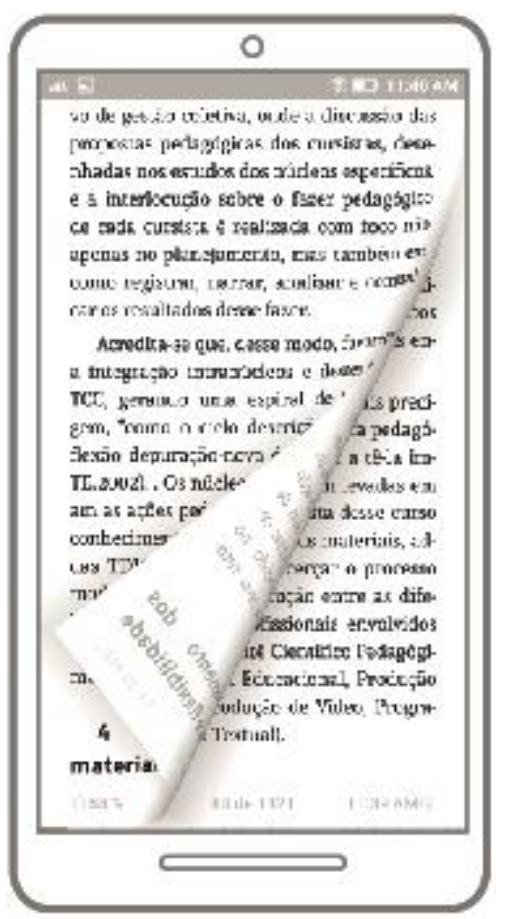

\section{Navegação não sequencial}

Poder navegar pelo texto de maneira não linear é normalmente um recurso bem suportado pelo meio digital. O Prestigio, como a maioria dos softwares, oferece opção de sumário interativo principal. Na tela de menu, uma barra de progresso interativa também possibilita ao leitor avançar ou retroceder rapidamente. Na parte inferior, a numeração de página é também editável, permitindo ao usuário digitar a página exata que pretende acessar.

O software também apresenta outros dois modos de navegação. Um é pela inserção de marcadores de página. As páginas que recebem a marcação passam a constituir um sumário que pode ser acessado no menu principal. O outro modo, é pela sumarização das notas em destaques como indicado na Figura 3. Assim como com os marcadores, estas podem ser acessadas no menu principal e levar o leitor a partes determinadas do texto. 
Figura 3: lista das páginas marcadas.

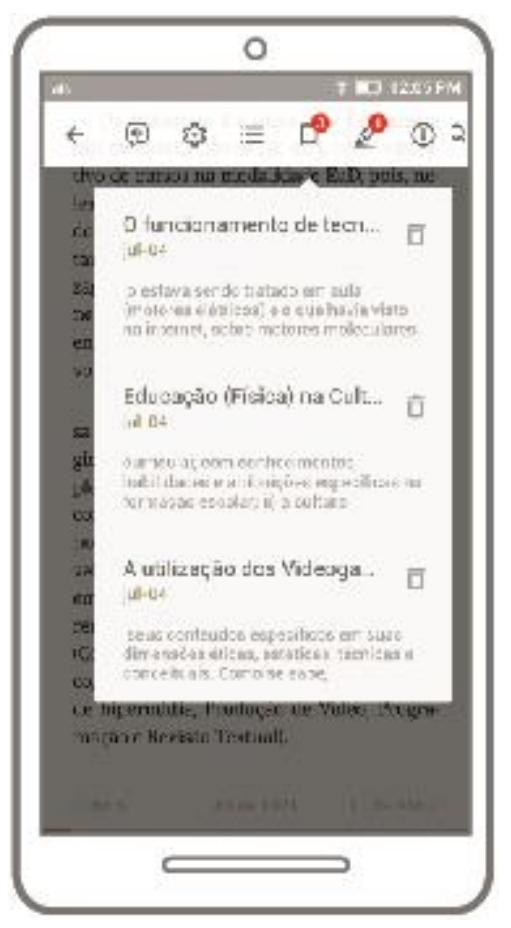

\section{Mapa cognitivo (consciência) do conteúdo}

Ao navegar por livro, um leitor costuma construir uma imagem mental do conteúdo. Assim, ele pode localizar certo trecho em um página, por exemplo, pela posição da mancha gráfica ou pela proximidade com algum outro elemento. Este recurso torna-se bastante comprometido na leitura de ebooks em formato EPUB, tendo que o layout é fluído e os elementos do texto mudam em função das dimensões da tela e da customização feita pelo usuário, como a alteração do tamanho de texto. Se a leitura é feita em smartphone, este requisito é mais difícil ainda de ser cumprido com o conteúdo particionado em muitas páginas.

\section{Leitura vertical}

A leitura vertical é praticada quando se quer ter uma visão geral do conteúdo. Percorre-se o texto fixando somente em elementos mais relevantes e em tópicos. Este tipo de leitura é muito deficiente em livros digitais, uma vez que em livros é possível folhear rapidamente, sem que haja atraso de renderização e travamentos. Com a tela reduzida do smartphone, esta atividade se compromete mais ainda.

\section{Troca de estilos de leitura}

A este requisito, Chen et al. (2012) se refere como a capacidade de alterar a interface para a adequação de diferentes necessidades de leitura. O Prestigio é bastante flexível em vários sentidos como indica a Figura 4.

O software oferece o modo de leitura noturno, com a inversão dos valores da imagem. Tem opção padrões de alterar o tamanho do texto, a largura da margem, a orientação da tela (vertical ou horizontal), o tipo de letra (diferentes famílias tipográficas). Porém, ainda oferece a opção de ajuste mais detalhado da apresentação gráfica, como alteração de cores da interface e customização dos estilos de texto.

O Prestigio ainda oferece a opção de leitor de texto. Pelo menu principal, o usuário pode selecionar esta opção e através de uma interface de áudio controlar a narração. É possível controlar a velocidade, tipo de voz e idioma. 
Figura 4: alterações na aparência do texto.

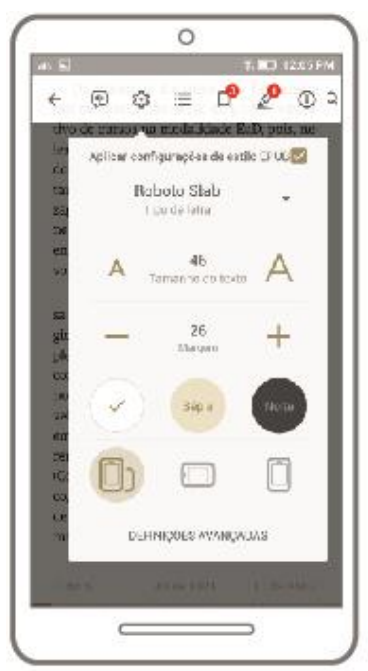

Alterações na aparência do texto.

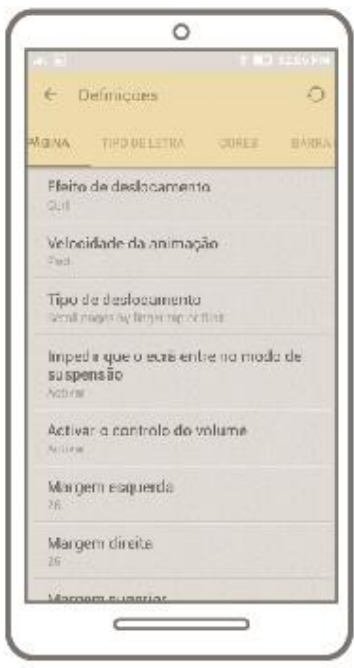

Alterações avançadas.

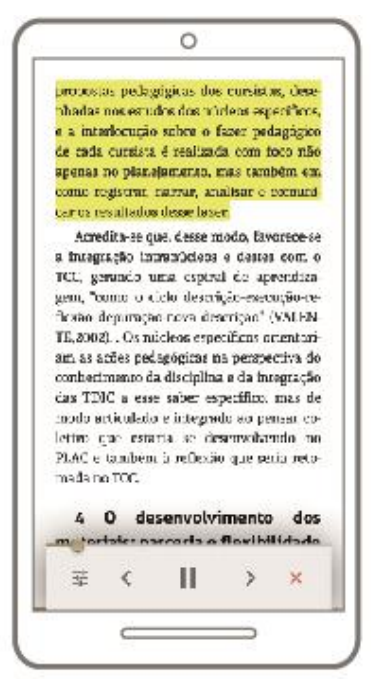

Ferramenta de leitor de texto.

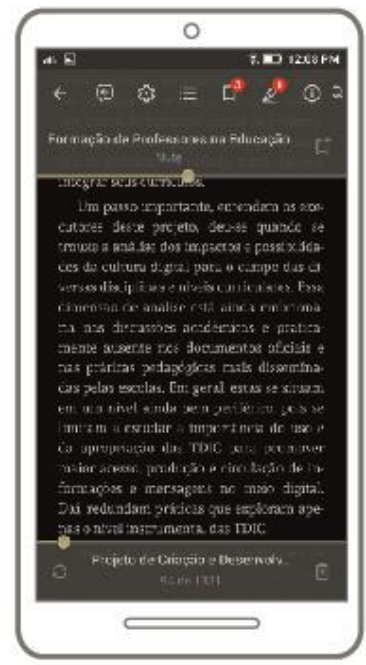

Polaridade invertidade da tela para leitura a noite.

\section{Discussões}

O Prestigio oferece algumas ferramentas significativas para lidar com as dificuldades causadas pela tela reduzida. A possibilidade de ampliação das imagens é uma delas. Considerando que a leitura ativa é praticada por estudantes e se dá sobre textos técnicos que apresentam tabelas e quadros, e outros dados em estruturas gráficas complexas, a ferramenta de ampliação é fundamental para a leitura em smartphone. A interação é um tanto custosa, dado que é preciso realizar muitos movimentos para ampliar e percorrer a imagem na tela, mas possibilita ao leitor, ao menos, ler o conteúdo com um mínimo de qualidade.

O software apresenta também opções para uma experiência de leitura personalizada. A possibilidade de escolha do tamanho e tipo de fonte, orientação da tela e cores da interface podem contribuir para uma adequação da leitura a diversos tipos de leitores. A ferramenta de leitor de texto, inclusive, permite a inclusão de leitores com necessidades especiais.

A avaliação indica que alguns requisitos não se cumprem em nível de hardware. A tela reduzida do smartphone dificulta a leitura, acarretando dificuldades em requisitos que se relacionam a uma navegação que exige uma leitura mais rápida, como retroceder para ler e a leitura vertical. A tela pequena também interfere na criação do mapa cognitivo do conteúdo. 0 caráter fluído do EPUB torna esse requisito inviável.

No entanto, os recursos de marcação tornam a navegação não sequencial como um fator relevante no aprimoramento da navegação. A possibilidade de criar marcadores de página e anotações, oportuniza ao usuário criar âncoras no texto que o permitem uma movimentação precisa e que, portanto, podem de alguma maneira amenizar os conflitos causados pela tela reduzida do smartphone. Ao criar listas de marcadores e anotações, o leitor de certa maneira estabelece um mapa cognitivo do conteúdo e pode com poucos cliques transitar por pontos diferentes.

Assim sendo, considerando que boa parte dos requisitos são atendidos em alto grau, o software pode contribuir para uma experiência positiva de leitura ativa em smartphone. Ainda que certos recursos sejam pouco práticos em comparação à leitura em papel, como a ferramenta de anotações, as opções de navegação se mostram como uma possibilidade eficaz de movimentação pelo texto e de suporte à leitura ativa.

\section{Conclusão}

Como a pesquisa indica, a leitura ativa se realiza na interação com vários textos. Ou seja, um estudante ou trabalhador intelectual dispõe de livros, tablets, cadernos e outros suportes para realizar a leitura. Do ponto de vista da interface do software ereader, a leitura ativa em smartphone mostra potencial para a integração ao processo. Os recursos apresentados pelo Prestigio indicam que existem possibilidades de aprimoramento de certos tipos de leitura em 
smartphone. Os recursos de marcação de página e anotação, como exemplos mais notáveis, se bem empregados, podem auxiliar na navegação não linear de maneira eficaz. Cabe salientar que estes recursos têm sido melhorados nos ereaders dedicados ao EPUB.

Abranger o processo de leitura ativa neste aparelho como um todo é inviável neste momento. Porém, dado que a mesma envolve todos os outros tipos de leitura e estas têm compatibilidade com variadas mídias, o smartphone pode, em certa medida fazer parte do processo.

Certamente que fatores cognitivos são impeditivos. Se confrontada com os leitores propostos por Santaella (2013), a leitura ativa parece ter relação com os perfis cognitivos constituídos antes da era digital. A relação entre este tipo de leitura e o perfil dos leitores dos tempos atuais é indicada por Baron (2015) como sendo conflituosa, dado que os leitores habituados ao uso de dispositivos móveis e ao grande volume de informação na redes apresentam dificuldades para uma leitura contínua, ainda mais se estes livros forem acessados em dispositivos móveis. Contudo, a leitura em smartphone é uma realidade e se mostra como uma tendência. A conveniência e pervasividade deste aparelho o torna uma opção para diversas atividades, ainda que empobrecidas do ponto de vista da experiência do usuário.

Como este estudo buscou indicar, a leitura ativa é um processo complexo e requer um suporte de melhor performance. A relação entre os níveis de interação dos ebooks constituem também uma complexidade que merece ser investigada em vista de uma adequação. Futuros estudos com o envolvimento de usuários podem contribuir para um aprofundamento sobre os requisitos deste tipo de leitura e sua relação com a interface do smartphone.

\section{Referências}

ADLER, Mortimer Jerome; DOREN, Charles Van. 2010. Como ler livros: O Guia Clássico para a Leitura Inteligente. São Paulo: É Realizações.

BALLARD, B. 2007. Designing the mobile user experience. West Sussex: John \& Sons.

BARON, N. 2015. Words Onscreen: the fate of reading in a Digital World. New York: Oxford University Press.

BONSIEPE, G. 2015. Do material ao digital. São Paulo: Blucher.

CHEN, N; GUIMBRETIERE, F.; SELLEN, A. 2012. Designing a multi-slate reading environment to support active reading activities. ACM Transactions on Computer-Human Interaction, v.19, n.3.

DAMÉ, G. 2014. Livro Eletrônico: um estudo prospectivo da leitura interativa. Dissertação não publicada. Programa de Pós-Graduação em Design e Expressão Gráfica. Universidade de Santa Catarina, Brasil.

DPT. 2015. From print to ebooks: a hybrid publishing toolkit for the arts. Amsterdã.

FRASCARA. J. 2011. ¿Qué es el diseño de información? Buenos Aires: Ediciones Infinito.

GRUSZYNSKI, A. C. 2015. Design editorial e publicação multiplataforma. Intexto, n. 34: 571588.

LEFFA, J. 1996. Fatores da Compreensão Na Leitura. Porto Alegre: Cadernos do IL.

LUPTON, E. 2014. Tipos na tela: um guia para designers, editores, tipógrafos, blogueiros e estudantes. São Paulo: Gustavo Gill.

MEIRELLES, F. 2017. Tecnologia de Informação: 28a pesquisa anual do Uso de TI. São Paulo: Fundação Getúlio Vargas.

NIELSEN, J.; BUDIU, R. 2014. Usabilidade Móvel. Rio de Janeiro: Elsevier.

NUNES, J.; GONÇALVES, B. 2016. Design de conteúdos educacionais digitais baseados em texto, acessados a partir de smartphones: uma revisão integrativa. Revista de design, Tecnologia e Sociedade, v.3, n.2: 150-166.

PREECE, J.; ROGERS, Y.; SHARP, H. 2013. Design de interação: além da interação homemcomputador. Porto Alegre: Bookman.

PROCÓPIO, E. 2010. O livro na Era Digital. São Paulo: Giz Editorial. 
SANTAELLA, L. 2013. Comunicação ubíqua: repercussões na cultura e na educação. São Paulo: Paulus.

STUMPF, A. 2013. A interação no livro digital em formato EPUB: potencialidades da hipermídia em obras histórico-regionais. Dissertação não publicada. Programa de Pós-Graduação em Design e Expressão Gráfica. Universidade de Santa Catarina, Brasil.

STUMPF, A, GONÇALVES. B. 2012. Leitura em revista. Cátedra UNESCO de Leitura PUC-Rio n. 4.

WISCHENBART, R. 2017. Global eBook: a report on market trends and developments. Vienna: Wischenbart Content and Consulting. 